\title{
Special Forum on "Social and Environmental Accounting and Accountability"
}

\section{Guest Editors: Charles Cho", Ericka Costa*, Giovanna Michelon*}

The purpose of this editorial is twofold. First, to present the reasons as to why we asked Financial Reporting to host a Special Forum on Social and Environmental Accounting and Accountability (SEAA) research. Second, to summarize the contributions that are published therein and provide Financial Reporting readers with insights on the hot topic of SEAA research today.

The idea of this Special Forum was conceived during a period in which Italian Academia was (and still is) undergoing many changes, including both an active involvement but also, and unfortunately, passive reforms - especially when these changes are brought into the system with a pronounced top-down approach. Undoubtedly, internationalization in Italy has become one of the major challenges and a sensitive topic in academic debates, particularly after the new national procedures on the accreditation to become Associate or Full Professor were put in place. Too often, internationalization is interpreted as the necessity to merely publish in international journals but we believe this outcome is "only" the result of a much more complex process. In fact, internationalization requires being open to new and different methodological approaches, being ready to identify relevant research questions with wide implications and, above all, the ability to work and study in an international environment and collaborate within an international network.

* ESSEC Business School.

${ }_{* * *}^{* *}$ University of Trento.

${ }^{* * *}$ University of Exeter and University of Padova. 
In this context, it appeared to us that one of the most growing stream of research internationally - that has also been traditionally a central object of investigation for the Italian accounting community - is indeed related to the demand from society for greater accountability and transparency in corporate reporting of the environmental and social impacts of corporate activities (OECD, 2004, 2010; Global Corporate Governance Forum, 2009). In response to these societal concerns, social and environmental reporting has received increasing attention from large publicly listed multinational corporations, small-and-medium enterprises, the public sector and not-for-profit organizations (KPMG, 2011). Social and environmental information is reported via a range of media, including annual reports, standalone sustainability or corporate social responsibility reports, websites, press releases and independent articles or reports. Initiatives such as the Global Reporting Initiative (GRI) are making attempts to extend and standardize the reporting of corporate environmental and social impacts, including those relating to human rights and indigenous rights. Moreover, recent corporate scandals have called for academic research to investigate some fundamental issues such as the nature of transition towards a "responsible" economic system, the role played by organizations in building (or not) sustainable development, their different disclosure practices and the way organizations' economic activities interact with their social and environmental dimensions.

This is where and how we came across the idea of developing this project in collaboration with the $4^{\text {th }}$ Italian Conference on Social and Environmental Accounting Research to which we have invited scholars working in this area to submit papers investigating a range of issues regarding social and environmental accounting and accountability as they pertain to a broad range of organizations and stakeholders. This conference is one of the numerous international meetings of the Centre for Social and Environmental Accounting Research (CSEAR), established in 1991 and based at the University of St. Andrews in Scotland since 2004. CSEAR is an international membershipbased organization with a newly elected Council and many active international associates worldwide forming the International Associates Committee. It aims at supporting students, practitioners, scholars and educators in all aspects of the education, research and practice of social, environmental and sustainability accounting, reporting, auditing, finance and taxation.

The $4^{\text {th }}$ Italian Conference on Social and Environmental Accounting Research was held in Trento on September $20^{\text {th }}$ and $21^{\text {st }} 2012$. Thirty papers were presented at the conference, which was attended by 41 delegates from more than ten different countries - Italy, Spain, the UK, Canada, Finland, Republic of South Africa, Australia, Bulgaria, France and Nigeria. Jeffrey 
Unerman (Royal Holloway University of London), Carlos Larrinaga (University of Burgos) and Jan Bebbington (University of St. Andrews) took part at the conference as guest speakers and enriched the debate from both theoretical and methodological points of view.

This event represented an important moment for the CSEAR Italian community as we were able to meet and discuss potential developments and future direction. During the conference, CSEAR members from the Italian community had the opportunity to talk about the "future" of the CSEAR community in Italy. As a result, thanks to the useful comments received during the meeting the Italian CSEAR members decided to concretely start building a more structured network based on shared actions, shared inter-university research projects on issues related to CSR and sustainability and shared ideas in order to be able to represent the CSEAR Italian community at the international level.

It was also our goal to make this Special Forum as international as possible. We received a total of six submissions - three from authors based in Italy and the three others from authors located outside Italy. We did our best to involve colleagues from various institutions and from different countries in the reviewing process and would like to take the opportunity here to thank them for their active support and their commitment to provide timely and helpful feedback to all submitted papers: Conny Beck, Emilio Boulianne, Massimo Contrafatto, Tiphaine Jérôme, Carlos Larrinaga, Hannele Mäkelä, Michelle Rodrigue and Angelo Russo.

The Special Forum on SEAA research includes three pieces - one is the outcome of the double-blind peer review process and the other two are invited contributions. The first invited contribution is authored by a prolific expert scholar in SEAA research, Professor Den Patten (Illinois State University). In his paper Den reviews the waves of CSR related research in mainstream journals, reflecting over both the positive and negative implications for the social and environmental accounting research community. The second invited contribution is written by two well-known sustainability expert professionals, Mark W. McElroy and Bill Baue (Center for Sustainable Organizations). Along the traditional editorial lines of Financial Reporting, we think that is extremely important to keep a tight link between academia and practice. This contribution addresses what are the research and development opportunities in the field of context-based sustainability. Finally, the third contribution by Enrico Bracci and Mouhcine Tallaki (University of Ferrara) is the only peer-reviewed articles and it investigates about the reasons for the adoption and eventual abandonment of social and environmental reporting by local government in Italy. 
Taken together, we believe (and hope) that these three contributions in the Special Forum will bring some solid and useful foundations in SEAA research to Financial Reporting readers, including those who are new and/or curious in this increasingly important. Given that each piece brings a different perspective in this area of investigation, all readers should be able to take away something valuable - research trends, links with practice or specific research context. We also believe that this Special Forum will provide additional useful and relevant insights for the advancement of the social accounting project (see Gray, 2002) and the improvement of human life quality.

\section{References}

Global Corporate Governance Forum (2009). Corporate governance: The foundation for corporate citizenship and sustainable businesses. Washington DC: GCGF.

Gray R. (2002). The social accounting project and Accounting Organizations and Society Privileging engagement, imaginings, new accountings and pragmatism over critique?, Accounting, Organizations and Society, 27(7), pp. 687708, doi: 10.1016/S0361-3682(00)00003-9.

KPMG (2011). KPMG International Survey of Corporate Responsibility Reporting. KPMG International Cooperative.

OECD (Organization for Economic Co-operation and Development) (2004). OECD principles of corporate governance. www.oecd.org.

OECD (Organization for Economic Co-operation and Development) (2010). Corporate Responsibility: Reinforcing a Unique Instrument - 2010 Annual Report on the OECD Guidelines for Multinational Enterprises. www.oecd.org. 